\title{
Epidemiological characteristics of 1385 primary sacral tumors in one institution in China
}

\author{
Jun Wang, Dasen Li, Rongli Yang, Xiaodong Tang, Taiqiang Yan and Wei Guo*
}

\begin{abstract}
Background: Sacral tumors and tumor-like lesions are a rare group of lesions that can affect children and adults of all ages. Little is known about clinical characteristics of age, gender, histologic type, and anatomic site in China.

Methods: A total of 1385 patients with sacral tumors and tumor-like lesions, which had the clinical record at our bone tumor center from January 2000 to November 2018 were analyzed. The metastatic cancers were not included in the present study.

Results: A total of 51.7\% (716 cases) were malignant and $48.3 \%$ (669 cases) were benign tumors or tumor-like lesions. Of malignant tumors, chordoma was the most common malignant tumor (316 cases, 22.8\% of all tumors), followed by chondrosarcoma, myeloma, and other histologic types. The most common histological type of benign tumors was a giant cell tumor accounting for 14.8\% (205 cases) of all tumors, followed by neurofibroma, schwannoma, and other types. The most common age group affected by malignant bone tumors was the 51- to 60-year-old group, followed by the 41- to 50-year-old group. The most commonly affected age group for benign tumors and tumor-like lesions was the 31- to 50-year-old group, followed by the 21- to 30-year old group. Furthermore, the following histologic types had gender predilection. Chordoma, chondrosarcoma, myeloma, and osteosarcoma affected more frequently males than females. Malignant peripheral nerve sheath tumor, lymphoma, giant cell tumor, neurofibroma, tuberculosis, teratoma, and epidermoid cyst more frequently affected females than males.

Conclusions: The large cohort of sacral tumors and tumor-like lesions in our database may reveal their clinical characteristics of age, gender, histologic type, and anatomic site in China and features of sacral tumors and tumor-like lesions are fairly distinct from the mobile spine and extremities.
\end{abstract}

Keywords: Primary sacral tumors, Epidemiology, Sacrum, Bone tumor

\section{Introduction}

Sacral tumors and tumor-like lesions are a rare group of tumors that can affect children and adults of all ages. Diagnosing a sacral tumor at an early stage is a great challenge because of the lack of specific clinical symptoms and sacral tumors are often extensively involved in the sacral nerves, iliac vessels, and other surrounding

\footnotetext{
* Correspondence: bonetumors@163.com

Musculoskeletal Tumor Center, Peking University People's Hospital, No. 11 Xizhimen South Street, Beijing 100044, China
}

organs. Furthermore, the management could be quite difficult for orthopedic surgeons because of its complicated anatomy and high risk of postoperative complications. The surgical treatment of these tumors has more difficult because of the complex regional anatomy. Surgeons must not only be familiar with local anatomy from a neurologic, colorectal, urologic, gynecological, orthopedic, and plastic standpoint but also sometimes have to face the dilemma between functional preservation and cure of the tumor [1-4].

C C The Author(s). 2020 Open Access This article is licensed under a Creative Commons Attribution 4.0 International License, which permits use, sharing, adaptation, distribution and reproduction in any medium or format, as long as you give appropriate credit to the original author(s) and the source, provide a link to the Creative Commons licence, and indicate if changes were made. The images or other third party material in this article are included in the article's Creative Commons licence, unless indicated otherwise in a credit line to the material. If material is not included in the article's Creative Commons licence and your intended use is not permitted by statutory regulation or exceeds the permitted use, you will need to obtain permission directly from the copyright holder. To view a copy of this licence, visit http://creativecommons.org/licenses/by/4.0/ The Creative Commons Public Domain Dedication waiver (http://creativecommons.org/publicdomain/zero/1.0/) applies to the data made available in this article, unless otherwise stated in a credit line to the data. 
A great number of specific histologic subtypes of them have been delineated, each of them with a unique appearance and biological potential [1, 2]. A barrier is presented to etiologic study due to the rarity and heterogeneity and it poses a great challenge in the understanding of clinical features [3]. Little is known about their clinical features of age, gender, histologic type, and anatomic site in China. China is a relatively big country with a steady population and the number of patients with sacral tumors and tumor-like lesions is huge and our hospital is the biggest specialized musculoskeletal tumor cancer in China. This provides us a beneficial condition to study clinical characteristics of sacral tumors and tumor-like lesions. The present study is aiming to provide the first analysis of features of age, gender, histologic type, and anatomic site for sacral tumors and tumor-like lesions not including metastatic cancers in our institution between January 2000 and November 2018.

\section{Patients and methods}

We retrospectively reviewed 1385 patients with sacral tumors and tumor-like lesions, which had the clinical record at our bone tumor center from January 2000 to November 2018. There were 709 male and 676 female patients with a mean age of $43.9 \pm 17.0$ years (range, 2 86 years). Histologic diagnosis was confirmed by biopsy or operative specimen. The inclusion criteria for the present study were as follows: (1) patients had the definitive histological diagnosis; (2) diagnostic time was from the year 2000 to 2018. The exclusion criteria were as follows: (1) without a confirmed histological diagnosis; (2) diagnostic time was beyond the range of 2000 to 2018; (3) metastatic cancers at the sacrum. All patients which were included in the present study were given written informed consent for their data to be included in this study during the follow-up. All data were obtained from the clinical and radiograph records. This study was approved by the Institutional Review Board/Ethics Committee of the authors' institution. The following data were collected in the present study: age, gender, affected sacrum level, pathological diagnosis. For the analysis of tumor location distribution, Region $S_{1}$ or $S_{2}$ or $S_{1-2}$ can be described as a high level of sacrum and Region $\mathrm{S}_{3}$ or below $\mathrm{S}_{3}$ as a low level of sacrum.

For the initial clinical evaluation and diagnosis, all patients received plain radiographs, CT, MRI, and bone scanning. After imaging, we performed the needle biopsy to clarify the diagnosis. For the malignant tumors, the routine follow-up including clinical examination, radiographs of the extremity and chest were performed every 3 months for the first 6 months, every 6 months for the first 3 years, and then annually. The chest CT scanning was performed every 6 months for the first 3 years, and then annually. For the benign tumors, the routine follow-up was performed every 6 months for the first year and then annually.

\section{Statistical analysis}

Continuous variables were summarized with means and ranges; categorical variables were summarized with frequency counts and percentages. The Student's $t$ test was used to compare the age in different histologic types of male and female in Tables 5 and 6 . The chi-square test was used to compare the location distribution in Table 7. The SPSS software (version 19.0; SPSS Inc, Chicago, IL, USA) was used for all statistical analyses. $P \leqq 0.05$ indicated a statistically significant difference.

\section{Results \\ Incidence of histological subtypes}

The histological types of sacral tumors and tumor-like lesions were listed in Tables 1 and 2. A total of 51.7\% (716 cases) were malignant and $48.3 \%$ (669 cases) were benign tumors and tumor-like lesions (Fig. 1). Of malignant tumors, chordoma was the most common malignant type of PST (22.8\% of all PST, 316 cases), followed by chondrosarcoma (5.3\%, 74 cases), myeloma (3.8\%, 53 cases), and malignant peripheral nerve sheath tumor (3.4\%, 47 cases) (Table 1). The most common histological type of benign tumors and tumor-like lesions was giant cell tumor accounting for $14.8 \%$ (205 cases), followed by neurofibroma (11.2\%, 155 cases), schwannoma ( $8.6 \%, 119$ cases), and tuberculosis (1.7\%, 24 cases) (Table 2). The top six of primary sacral tumors were summarized in Fig. 2.

\section{Age distribution of sacral tumors and tumor-like lesions}

For a total of 1385 sacral tumors and tumor-like lesions, the mean age was $43.9 \pm 17.0$ years (range, $2-86$ years), $51.2 \%$ (709 cases) of the lesions occurred in males and $48.8 \%$ (676 cases) in females, with a mean age of $44.5 \pm$ 17.2 and $43.1 \pm 16.7$ years. The mean age of 716 malignant and 669 benign tumors and tumor-like lesions groups were respectively $46.9 \pm 17.5$ years (range, $2-86$ years) and $40.6 \pm 15.7$ years (range, $2-85$ years).

The incidences were presented separately by gender (males and females) and age at diagnosis was grouped into nine subgroups (from 0 to 10 years cohort to $\geq 80$ years cohort). The most common age group affected by malignant bone tumors was the 51- to 60 year-old group $(21.1 \%, 151$ cases $)$, followed by the 41 to 50-year-old group (19.4\%, 139 cases) (Table 3). The most commonly affected age group for benign tumors and tumor-like lesions were the 31- to 40year-old and 41- to 50-year-old groups (21.1\%, 141 cases and $21.1 \%, 141$ cases), followed by the 21- to 30 -year old group (19.6\%, 131 cases) (Table 4). 
Table 1 Histopathological diagnosis of 716 patients with sacral malignant tumors

\begin{tabular}{|c|c|c|}
\hline Primary malignant tumor & No.(percentage) in malignant tumors & No.(percentage) in all patients \\
\hline Chordoma & $316(44.1 \%)$ & $316(22.8 \%)$ \\
\hline Chondrosarcoma & $74(10.3 \%)$ & $74(5.3 \%)$ \\
\hline Myeloma & $53(7.4 \%)$ & $53(3.8 \%)$ \\
\hline Malignant peripheral nerve sheath tumor & $47(6.6 \%)$ & 47 (3.4\%) \\
\hline Ewing sarcoma & $47(6.6 \%)$ & 47 (3.4\%) \\
\hline Osteosarcoma & $40(5.6 \%)$ & $40(2.9 \%)$ \\
\hline Lymphoma & $35(4.9 \%)$ & $35(2.5 \%)$ \\
\hline Solitary fibrous tumor & $20(2.8 \%)$ & $20(1.4 \%)$ \\
\hline Undifferentiated pleomorphic sarcoma & $17(2.4 \%)$ & $17(1.2 \%)$ \\
\hline Malignant giant cell tumor & $17(2.4 \%)$ & $17(1.2 \%)$ \\
\hline Malignant teratoma & $11(1.5 \%)$ & $11(0.8 \%)$ \\
\hline Liposarcoma & $10(1.4 \%)$ & $10(0.7 \%)$ \\
\hline Ependymoma & $4(0.6 \%)$ & $4(0.3 \%)$ \\
\hline Angiosarcoma & $3(0.4 \%)$ & $3(0.2 \%)$ \\
\hline Fibrosarcoma & $3(0.4 \%)$ & $3(0.2 \%)$ \\
\hline Hemangioendothelima & $3(0.4 \%)$ & $3(0.2 \%)$ \\
\hline Myelocytic sarcoma & $3(0.4 \%)$ & $3(0.2 \%)$ \\
\hline Yolk sac tumor & $3(0.4 \%)$ & $3(0.2 \%)$ \\
\hline Leiomyosarcoma & $2(0.3 \%)$ & $2(0.1 \%)$ \\
\hline Alveolar soft part sarcoma & $2(0.3 \%)$ & $2(0.1 \%)$ \\
\hline Leukemia & $2(0.3 \%)$ & $2(0.1 \%)$ \\
\hline Epithelioid sarcoma & $1(0.1 \%)$ & $1(0.07 \%)$ \\
\hline Granulocyte sarcoma & $1(0.1 \%)$ & $1(0.07 \%)$ \\
\hline Myofibroblastic sarcoma & $1(0.1 \%)$ & $1(0.07 \%)$ \\
\hline Synovial sarcoma & $1(0.1 \%)$ & $1(0.07 \%)$ \\
\hline
\end{tabular}

We analyzed the age and gender-related clinical characteristics of the top seven primary sacral malignant tumors (Fig. 3). Of 316 chordomas, the mean age was 55.4 \pm 13.7 (range, $18-86$ years) and 210 cases occurred in males and 106 cases in females, with a mean age of 56.1 \pm 13.3 and $54.1 \pm 14.4$ years. Of 74 chondrosarcoma, the mean age was $40.9 \pm 13.3$ (range, 17-69 years) and 41 cases occurred in males and 33 cases in females, with a mean age of $37.7 \pm 14.8$ and $44.9 \pm 10.0$ years. Of 53 myeloma, the mean age was $54.1 \pm 13.2$ (range, 22-78 years) and 41 cases occurred in males and 33 cases in females, with a mean age of $53.4 \pm 14.4$ and $55.6 \pm 10.6$ years. Of 47 malignant peripheral nerve sheath tumors, the mean age was $40.8 \pm 16.7$ (range, $8-75$ years) and 19 cases occurred in males and 28 cases in females, with a mean age of $40.4 \pm 18.3$ and $41.0 \pm 15.8$ years (Table 5 ). Moreover, we analyzed the age and gender-related clinical characteristics of the top seven primary sacral benign tumors and tumor-like lesions (Fig. 3). Of 205 giant cell tumors, the mean age was $34.4 \pm 11.6$ (range, 11-67 years) and 69 cases occurred in males and 86 cases in females, with a mean age of $32.7 \pm 10.3$ and $35.8 \pm 12.5$ years. Of 155 neurofibroma, the mean age was $46.7 \pm$ 14.5 (range, 9-83 years) and 95 cases occurred in males and 110 cases in females, with a mean age of $44.6 \pm 13.8$ and $48.4 \pm 14.9$ years. Of 119 schwannoma, the mean age was $46.1 \pm 13.5$ (range, 13-79 years) and 60 cases occurred in males and 59 cases in females, with a mean age of $44.6 \pm 13.1$ and $47.7 \pm 13.9$ years (Table 6).

\section{Gender characteristics of sacral tumors and tumor-like lesions}

The distribution of different histological types in males and females was shown as follows (Fig. 4): chordoma (316 cases, $\mathrm{M}: \mathrm{F}=1.98: 1$ ), chondrosarcoma (74 cases, $\mathrm{M}: \mathrm{F}=1.24: 1$ ), myeloma (53 cases, $\mathrm{M}: \mathrm{F}=2.12: 1)$, and osteosarcoma (40 cases, $\mathrm{M}: \mathrm{F}=1.35: 1$ ) affected more frequently males than females. Meanwhile, malignant peripheral nerve sheath tumor (47 cases, $\mathrm{M}: \mathrm{F}=0.68: 1$ ), lymphoma (35 cases, $\mathrm{M}: \mathrm{F}=0.75: 1$ ), giant cell tumor (205 cases, $\mathrm{M}: \mathrm{F}=0.86: 1)$, neurofibroma (155 cases, $\mathrm{M}$ : $\mathrm{F}=0.80: 1)$, tuberculosis $(24$ cases, $\mathrm{M}: \mathrm{F}=0.50: 1)$, 
Table 2 Histopathological diagnosis of 669 patients with sacral benign tumors and tumor-like lesions

\begin{tabular}{|c|c|c|}
\hline Primary benign tumor & No.(percentage) in BT/TLL & No.(percentage) in all patients \\
\hline Giant cell tumor & $205(30.6 \%)$ & $205(14.8 \%)$ \\
\hline Neurofibroma & $155(23.2 \%)$ & $155(11.2 \%)$ \\
\hline Schwannoma & $119(17.8 \%)$ & 119 (8.6\%) \\
\hline Tuberculosis & $24(3.6 \%)$ & $24(1.7 \%)$ \\
\hline Teratoma & $23(3.4 \%)$ & $23(1.7 \%)$ \\
\hline Sacral canal cysts & $22(3.3 \%)$ & $22(1.6 \%)$ \\
\hline Epidermoid cyst & $21(3.1 \%)$ & $21(1.5 \%)$ \\
\hline Hemangioma & $14(2.1 \%)$ & $14(1.0 \%)$ \\
\hline Meningeal cysts & $13(1.9 \%)$ & $13(0.9 \%)$ \\
\hline Primary aneurysmal bone cyst & $12(1.8 \%)$ & $12(0.9 \%)$ \\
\hline Fibrous dysplasia & $9(1.3 \%)$ & $9(0.6 \%)$ \\
\hline Osteoblastoma & $9(1.3 \%)$ & $9(0.6 \%)$ \\
\hline Eosinophilic granuloma & $7(1.0 \%)$ & $7(0.5 \%)$ \\
\hline Simple bone cyst & $5(0.7 \%)$ & $5(0.4 \%)$ \\
\hline Spinal meningioma & $5(0.7 \%)$ & $5(0.4 \%)$ \\
\hline Gut-tail cyst & $4(0.6 \%)$ & $4(0.3 \%)$ \\
\hline Benign fibrous histiocytoma & $4(0.6 \%)$ & $4(0.3 \%)$ \\
\hline Fibromatosis & $3(0.4 \%)$ & $3(0.2 \%)$ \\
\hline Diffuse giant cell tumor of tendon sheath & $3(0.4 \%)$ & $3(0.2 \%)$ \\
\hline Chondroblastoma & $3(0.4 \%)$ & $3(0.2 \%)$ \\
\hline Lipoma & $2(0.3 \%)$ & $2(0.1 \%)$ \\
\hline Phosphouria stromal tumor & $2(0.3 \%)$ & $2(0.1 \%)$ \\
\hline Osteoidosteoma & $2(0.3 \%)$ & $2(0.1 \%)$ \\
\hline Leiomyoma & $1(0.1 \%)$ & $1(0.07 \%)$ \\
\hline Paget disease & $1(0.1 \%)$ & $1(0.07 \%)$ \\
\hline Osteochondroma & $1(0.1 \%)$ & $1(0.07 \%)$ \\
\hline
\end{tabular}

BT/TLL benign tumor and tumor-like lesions

teratoma ( 23 cases, $\mathrm{M}: \mathrm{F}=0.21: 1)$ and epidermoid cyst (21 cases, $\mathrm{M}: \mathrm{F}=0.24: 1)$ affected more frequently females than males (Tables 5 and 6).

\section{Location distribution of sacral tumors and tumor-like lesions}

To distinguish the high or low level was more important for the design of surgical strategy. Thus, we analyzed the location distribution of all tumors. For the malignant tumors, 412 were located at the region of above $S_{3}$ and 304 tumors were at the $S_{3}$ /below $S_{3}$. For the benign tumors, 485 were located at the region of above $S_{3}$ and 184 tumors were at the $S_{3}$ /below $S_{3}$. Chordoma and giant cell tumors are the top two histologic types of tumors at the sacrum. Among 316 cases with chordoma, only five $(1.6 \%, 5 / 316)$ were located at Region $S_{1}$ to $S_{2}$, $145(45.9 \%, 145 / 316)$ being at Region $S_{3}$ and below $S_{3}$ and $166(52.5 \%, 166 / 316)$ were associated with both two regions. Meanwhile, among 205 cases with giant cell tumor, eighty tumors $(39 \%, 80 / 205)$ were located at
Region $S_{1}$ to $S_{2}$ and $114(55.6 \%, 114 / 205)$ cases were associated with both two regions. Only eleven giant cell tumors were located at Region $\mathrm{S}_{3}$ and below $\mathrm{S}_{3}$. Notably, there was a significant difference in location distribution between chordoma and giant cell tumor (Table 7). We showed typical cases with chordoma and giant cell tumor in different regions of the sacrum (Fig. 5). Chordoma usually originated at the low level of the sacrum and extended upward and forward. Giant cell tumor often stemmed from the high level of the sacrum and destroyed the lower level. This characteristic was more useful to distinguish chordoma from the giant cell tumor.

\section{Discussion}

This series of primary sacral tumors and tumor-like lesions treated at our tumor center provides valuable data of clinical characteristics contributing to our understanding of the diagnosis and therapy for lesions at the sacrum in the clinical practice. Available reports on 

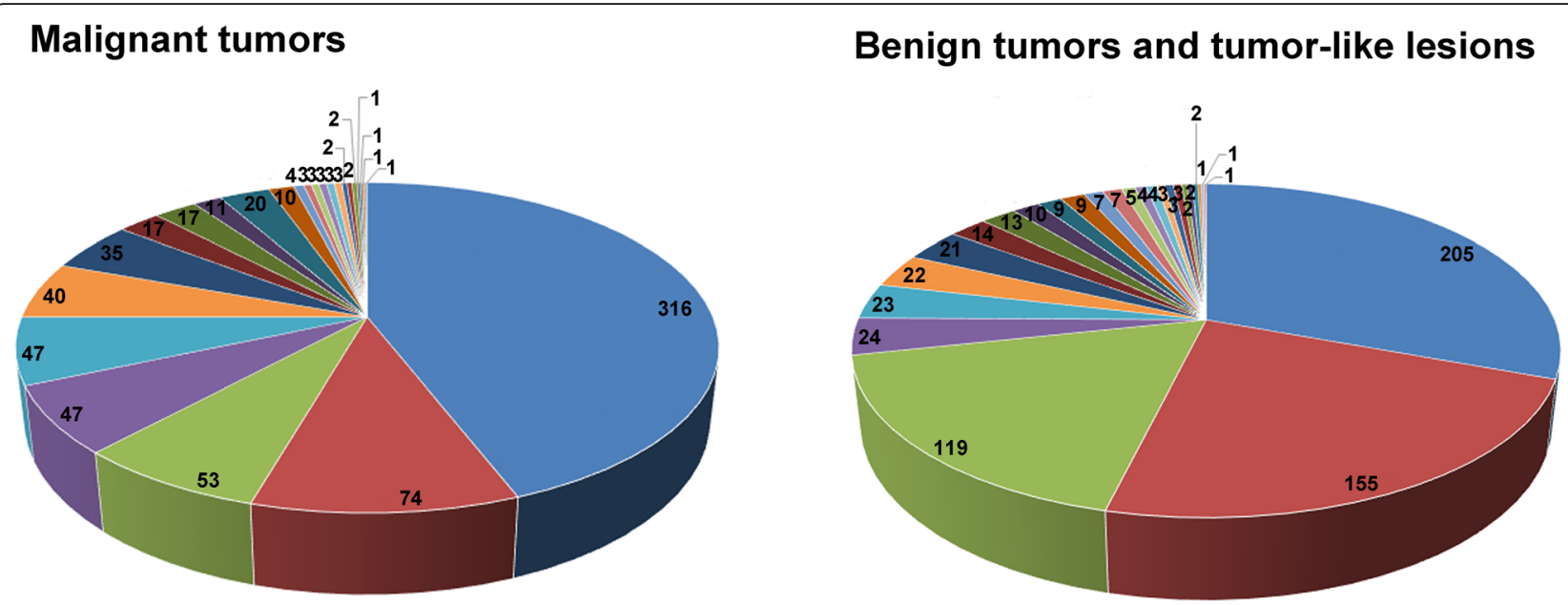

Fig. 1 Malignant tumors Chordoma (316, 44.1\%); Chondrosarcoma (74, 10.3\%); Multiple myeloma (53, 7.4\%); Malignant peripheral nerve sheath tumor (47, 6.6\%); Ewing sarcoma (47, 6.6\%); Osteosarcoma (40, 5.6\%); Lymphoma (35, 4.9\%); Solitary fibrous tumor (20, 2.8\%); Spindle cell undifferentiated sarcoma (17, 2.4\%); Malignant giant cell tumor (17, 2.4\%); Malignant teratoma (11, 1.5\%); Liposarcoma (10, 1.4\%); Ependymoma (4, 0.6\%); Angiosarcoma (3, 0.4\%); Fibrosarcoma (3, 0.4\%); Hemangioendothelima (3, 0.4\%); Myelocytic sarcoma (3, 0.4\%); Yolk sac tumor (3, 0.4\%); Leiomyosarcoma (2, 0.3\%); Alveolar soft part sarcoma (2, 0.3\%); Leukemia (2, 0.3\%); Epithelioid sarcoma (1, 0.1\%); Granulocyte sarcoma (1,0.1\%); Myofibroblastic sarcoma (1, 0.1\%); Synovial sarcoma (1, 0.1\%) Benign tumors and tumor-like lesions Giant cell tumor (205, 30.6\%);

Neurofibroma (155, 23.2\%); Schwannoma (119, 17.8\%); Tuberculosis (24, 3.6\%); Teratoma (23, 3.4\%); Sacral canal cysts (22, 3.3\%); Epidermoid cyst (21, 3.1\%); Hemangioma (14, 2.1\%); Meningeal cysts (13, 1.9\%); Primary aneurysmal bone cyst (10, 1.5\%); Fibrous dysplasia (9, 1.3\%); Osteoblastoma (9, 1.3\%); Eosinophilic granuloma (7, 1.0\%); Simple bone cyst (7, 1.0\%); Spinal meningioma (5, 0.7\%); Gut-tail cyst (4, 0.6\%); Benign fibrous histiocytoma (4, 0.6\%); Fibromatosis (3, 0.4\%); Diffuse giant cell tumor of tendon sheath (3, 0.4\%); Chondroblastoma (3, 0.4\%); Lipoma (2, 0.3\%); Phosphouria stromal tumor (2, 0.3\%); Osteoidosteoma (2, 0.3\%); Liomyoma (1, 0.1\%); Paget disease (1, 0.1\%); Osteochondroma (1, 0.1\%)

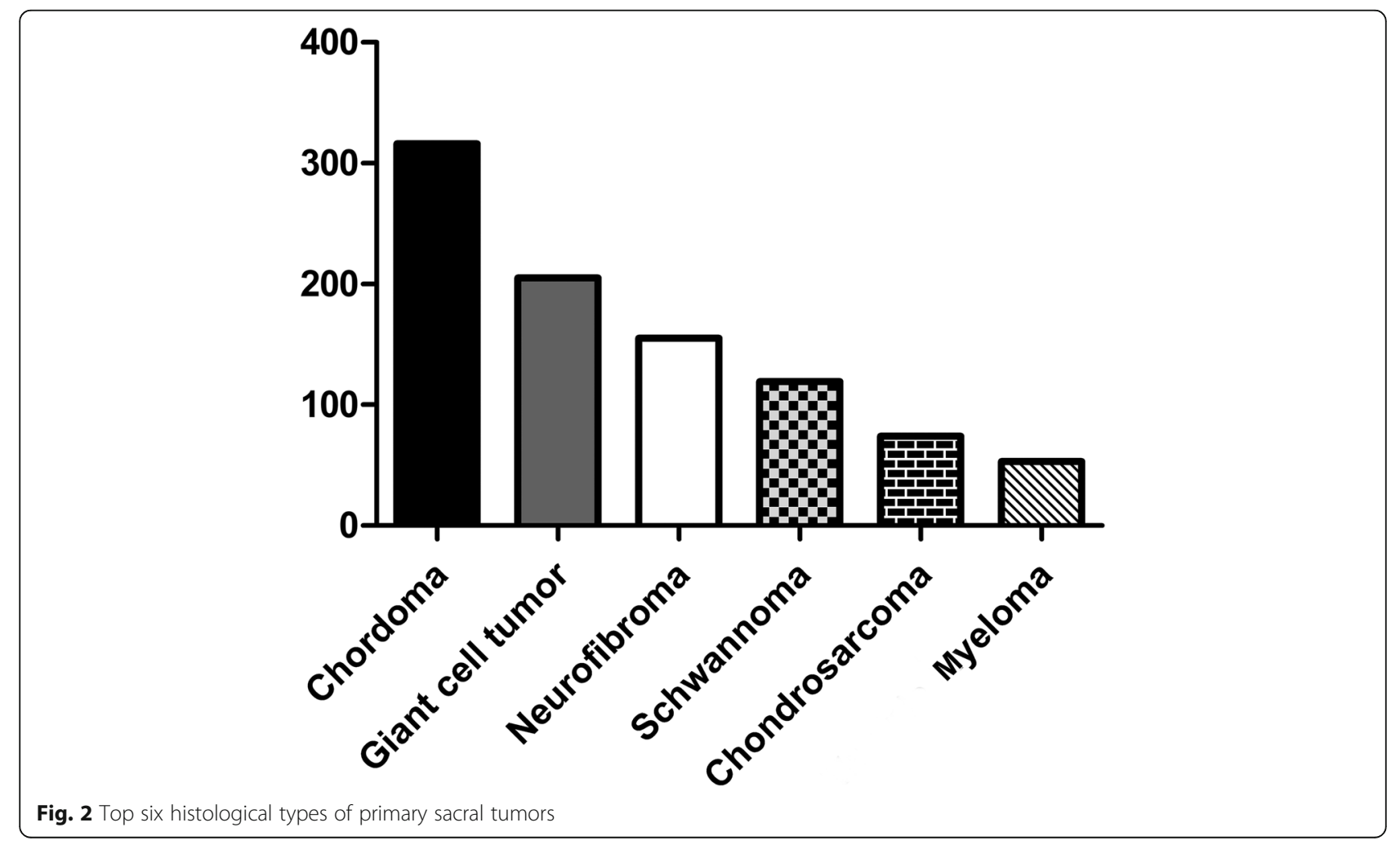


Table 3 Age distribution of sacral malignant tumors

\begin{tabular}{|c|c|c|c|c|c|c|c|c|c|c|}
\hline Histology & $0-10$ & $11-20$ & $21-30$ & $31-40$ & $41-50$ & $51-60$ & $61-70$ & $71-80$ & $81-90$ & Total \\
\hline Malignant tumors & $9(1.3 \%)$ & $54(7.5 \%)$ & $88(12.3 \%)$ & $96(13.4 \%)$ & 139(19.4\%) & 151(21.1\%) & $122(17.0 \%)$ & $52(7.3 \%)$ & $5(0.7 \%)$ & 716 \\
\hline Chordoma & $0(0)$ & $1(0.3 \%)$ & $17(5.4 \%)$ & $29(9.2 \%)$ & $58(18.4 \%)$ & $85(26.9 \%)$ & $82(25.9 \%)$ & $39(12.3 \%)$ & $5(1.6 \%)$ & 316 \\
\hline Chondrosarcoma & $0(0)$ & $5(6.8 \%)$ & 14(18.9\%) & $16(21.6 \%)$ & 19(25.7\%) & $16(21.6 \%)$ & $4(5.4 \%)$ & $0(0)$ & $0(0)$ & 74 \\
\hline Myeloma & $0(0)$ & $0(0)$ & $2(3.8 \%)$ & $7(13.2 \%)$ & $13(24.5 \%)$ & $13(24.5 \%)$ & $12(22.6 \%)$ & $6(11.3 \%)$ & $0(0)$ & 53 \\
\hline $\begin{array}{l}\text { Malignant peripheral nerve sheath } \\
\text { tumor }\end{array}$ & $1(2.1 \%)$ & $5(10.6 \%)$ & $10(21.3 \%)$ & $5(10.6 \%)$ & $11(23.4 \%)$ & $9(19.1 \%)$ & $5(10.6 \%)$ & $1(2.1 \%)$ & $0(0)$ & 47 \\
\hline Ewing sarcoma & $5(10.6 \%)$ & 19(40.4\%) & $9(19.1 \%)$ & $9(19.1 \%)$ & $4(8.5 \%)$ & $1(2.1 \%)$ & $0(0)$ & $0(0)$ & $0(0)$ & 47 \\
\hline Osteosarcoma & $1(2.5 \%)$ & $15(37.5 \%)$ & $13(32.5 \%)$ & $5(12.5 \%)$ & $3(7.5 \%)$ & $3(7.5 \%)$ & $0(0)$ & $0(0)$ & $0(0)$ & 40 \\
\hline Lymphoma & $0(0)$ & $2(5.7 \%)$ & $4(11.4 \%)$ & $5(14.3 \%)$ & $9(25.7 \%)$ & $9(25.7 \%)$ & $4(11.4 \%)$ & $2(5.7 \%)$ & $0(0)$ & 35 \\
\hline Solitary fibrous tumor & $0(0)$ & $0(0)$ & $4(20 \%)$ & $5(25 \%)$ & $4(20 \%)$ & $2(10 \%)$ & $4(20 \%)$ & $1(5 \%)$ & $0(0)$ & 20 \\
\hline Undifferentiated pleomorphic sarcoma & $0(0)$ & $0(0)$ & $1(5.9 \%)$ & $2(11.8 \%)$ & $3(17.6 \%)$ & $5(29.4 \%)$ & $4(23.5 \%)$ & $2(11.8 \%)$ & $0(0)$ & 17 \\
\hline Malignant giant cell tumor & $0(0)$ & $2(11.8 \%)$ & $6(35.3 \%)$ & $4(23.5 \%)$ & $2(11.8 \%)$ & $2(11.8 \%)$ & $1(5.9 \%)$ & $0(0)$ & $0(0)$ & 17 \\
\hline Malignant teratoma & $0(0)$ & $0(0)$ & $2(18.2 \%)$ & $4(36.4 \%)$ & $1(9.1 \%)$ & $2(18.2 \%)$ & $2(18.2 \%)$ & $0(0)$ & $0(0)$ & 11 \\
\hline Liposarcoma & $0(0)$ & $0(0)$ & $0(0)$ & $2(20.0 \%)$ & $4(40.0 \%)$ & $1(10.0 \%)$ & $3(30.0 \%)$ & $0(0)$ & $0(0)$ & 10 \\
\hline Ependymoma & $0(0)$ & $0(0)$ & $1(25.0 \%)$ & $0(0)$ & $2(50.0 \%)$ & $0(0)$ & $0(0)$ & $1(25.0 \%)$ & $0(0)$ & 4 \\
\hline Angiosarcoma & $0(0)$ & $0(0)$ & $0(0)$ & $0(0)$ & 1(33.3\%) & $2(67.7 \%)$ & $0(0)$ & $0(0)$ & $0(0)$ & 3 \\
\hline Fibrosarcoma & $0(0)$ & $1(33.3 \%)$ & $0(0)$ & $0(0)$ & $2(67.7 \%)$ & $0(0)$ & $0(0)$ & $0(0)$ & $0(0)$ & 3 \\
\hline Hemangioendothelima & $1(33.3 \%)$ & $0(0)$ & $0(0)$ & $1(33.3 \%)$ & $0(0)$ & $0(0)$ & $1(33.3 \%)$ & $0(0)$ & $0(0)$ & 3 \\
\hline Myelocytic sarcoma & $0(0)$ & $0(0)$ & $1(33.3 \%)$ & $2(67.7 \%)$ & $0(0)$ & $0(0)$ & $0(0)$ & $0(0)$ & $0(0)$ & 3 \\
\hline Yolk sac tumor & $1(33.3 \%)$ & $2(67.7 \%)$ & $0(0)$ & $0(0)$ & $0(0)$ & $0(0)$ & $0(0)$ & $0(0)$ & $0(0)$ & 3 \\
\hline Leiomyosarcoma & $0(0)$ & $0(0)$ & $1(50.0 \%)$ & $0(0)$ & $1(50.0 \%)$ & $0(0)$ & $0(0)$ & $0(0)$ & $0(0)$ & 2 \\
\hline Alveolar soft part sarcoma & $0(0)$ & $0(0)$ & $2(100.0 \%)$ & $0(0)$ & $0(0)$ & $0(0)$ & $0(0)$ & $0(0)$ & $0(0)$ & 2 \\
\hline Leukemia & $0(0)$ & $1(50.0 \%)$ & $0(0)$ & $0(0)$ & $1(50.0 \%)$ & $0(0)$ & $0(0)$ & $0(0)$ & $0(0)$ & 2 \\
\hline Epithelioid sarcoma & $0(0)$ & $1(100.0 \%)$ & $0(0)$ & $0(0)$ & $0(0)$ & $0(0)$ & $0(0)$ & $0(0)$ & $0(0)$ & 1 \\
\hline Granulocyte sarcoma & $0(0)$ & $0(0)$ & $0(0)$ & $0(0)$ & $1(100.0 \%)$ & $0(0)$ & $0(0)$ & $0(0)$ & $0(0)$ & 1 \\
\hline Myofibroblastic sarcoma & $0(0)$ & $0(0)$ & $0(0)$ & $0(0)$ & $0(0)$ & $1(100.0 \%)$ & $0(0)$ & $0(0)$ & $0(0)$ & 1 \\
\hline Synovial sarcoma & $0(0)$ & $0(0)$ & $1(100.0 \%)$ & $0(0)$ & $0(0)$ & $0(0)$ & $0(0)$ & $0(0)$ & $0(0)$ & 1 \\
\hline
\end{tabular}

clinical features of primary spine tumors and tumor-like lesions were mostly among the mobile spine $[1,4,5]$. There are not enough studies to reveal the clinical characteristics of patients with sacral tumor and tumor-like lesions in China. In the literature review, Zhou et al. reported 68 benign and 134 malignant sacral tumors in the analysis of clinical features for spine tumors. In their study, giant cell tumor, hemangioma, and solitary bone cyst were the top three benign tumors meanwhile chordoma, malignant neurilemmoma, and chondrosarcoma were the top three malignant tumors. The incidence characteristic of their malignant tumors was basically similar to our cohort. Nevertheless, the rate of their benign tumors was distinct from ours. This may be related to their limited sacral case numbers. The present report demonstrated clinical characteristics of age, gender, histologic type, and anatomic site based on the largest series of sacral tumors and tumor-like lesions.
Clinical characteristics of patients with sacral tumor and tumor-like lesions could help us to perform the differential diagnosis. Chordoma, chondrosarcomas, myeloma, and lymphoma more frequently occurs at the older age, otherwise, osteosarcoma and Ewing sarcoma are more frequent at a young age. Chordoma and teratoma are commonly located at the lower level. For malignant tumors, osteosarcoma, myeloma, and chordoma at the sacrum have male predilection while MPNST is more frequent in female population. For benign tumors and tumor-like lesions, epidermoid cyst and teratoma have the obvious female predilection.

In our series, chordoma was the most common primary malignant tumor, accounting for 44.1\% (316/716), followed by chondrosarcoma $(10.3 \%, 74 / 716)$, myeloma (7.4\%, 53/716), malignant peripheral nerve sheath tumor (6.6\%, 47/716), Ewing sarcoma $(6.6 \%, 47 / 716)$, osteosarcoma $(5.6 \%, 40 / 716)$, and lymphoma $(4.9 \%, 35 / 716)$. 
Table 4 Age distribution of sacral benign tumors and tumor-like lesions

\begin{tabular}{|c|c|c|c|c|c|c|c|c|c|c|}
\hline Histology & $0-10$ & $11-20$ & $21-30$ & $31-40$ & $41-50$ & $51-60$ & $61-70$ & $71-80$ & $81-90$ & Total \\
\hline Primary benign tumor & $11(1.6 \%)$ & $58(8.7 \%)$ & $131(19.6 \%)$ & $141(21.1 \%)$ & $141(21.1 \%)$ & 108(16.1\%) & $60(9.0 \%)$ & $16(2.4 \%)$ & $3(0.4 \%)$ & 669 \\
\hline Giant cell tumor & $0(0)$ & $24(11.7 \%)$ & $61(29.8 \%)$ & $62(30.2 \%)$ & $40(19.5 \%)$ & $12(5.9 \%)$ & $6(2.9 \%)$ & $0(0)$ & $0(0)$ & 205 \\
\hline Neurofibroma & $1(0.6 \%)$ & $6(3.9 \%)$ & 18(11.6\%) & $24(15.5 \%)$ & $39(25.2 \%)$ & $41(26.5 \%)$ & $20(12.9 \%)$ & $5(3.2 \%)$ & $1(0.6 \%)$ & 155 \\
\hline Schwannoma & $0(0)$ & $2(1.7 \%)$ & 16(13.4\%) & $24(20.2 \%)$ & $33(27.7 \%)$ & $24(20.2 \%)$ & $16(13.4 \%)$ & $4(3.4 \%)$ & $0(0)$ & 119 \\
\hline Tuberculosis & $1(4.2 \%)$ & $2(8.3 \%)$ & $4(16.7 \%)$ & $5(20.8 \%)$ & $4(16.7 \%)$ & $4(16.7 \%)$ & $1(4.2 \%)$ & $3(12.5 \%)$ & $0(0)$ & 24 \\
\hline Teratoma & $1(4.3 \%)$ & $3(13.0 \%)$ & $8(34.8 \%)$ & $6(26.1 \%)$ & $3(13.0 \%)$ & $1(4.3 \%)$ & $1(4.3 \%)$ & $0(0)$ & $0(0)$ & 23 \\
\hline Sacral canal cysts & $0(0)$ & $1(4.5 \%)$ & $3(13.6 \%)$ & $4(18.2 \%)$ & $3(13.6 \%)$ & $4(18.2 \%)$ & $6(27.3 \%)$ & $0(0)$ & $1(4.5 \%)$ & 22 \\
\hline Epidermoid cyst & $0(0)$ & $2(9.5 \%)$ & $3(14.3 \%)$ & $2(9.5 \%)$ & $5(23.8 \%)$ & $4(19.0 \%)$ & $2(9.5 \%)$ & $3(14.3 \%)$ & $0(0)$ & 21 \\
\hline Hemangioma & $1(7.1 \%)$ & $2(14.3 \%)$ & $1(7.1 \%)$ & $2(14.3 \%)$ & $1(7.1 \%)$ & $4(28.6 \%)$ & $1(7.1 \%)$ & $1(7.1 \%)$ & $1(7.1 \%)$ & 14 \\
\hline Meningeal cysts & $0(0)$ & $1(7.7 \%)$ & $1(7.7 \%)$ & $1(7.7 \%)$ & $1(7.7 \%)$ & $6(46.2 \%)$ & $3(23.1 \%)$ & $0(0)$ & $0(0)$ & 13 \\
\hline $\begin{array}{l}\text { Primary aneurysmal } \\
\text { bone cyst }\end{array}$ & $2(16.7 \%)$ & $8(66.7 \%)$ & $1(8.3 \%)$ & $0(0)$ & $1(8.3 \%)$ & $0(0)$ & $0(0)$ & $0(0)$ & $0(0)$ & 12 \\
\hline Fibrous dysplasia & $0(0)$ & 1(11.1\%) & $2(22.2 \%)$ & $3(33.3 \%)$ & $2(22.2 \%)$ & $1(11.1 \%)$ & $0(0)$ & $0(0)$ & $0(0)$ & 9 \\
\hline Osteoblastoma & $3(33.3 \%)$ & $3(33.3 \%)$ & $1(11.1 \%)$ & $0(0)$ & $1(11.1 \%)$ & $1(11.1 \%)$ & $0(0)$ & $0(0)$ & $0(0)$ & 9 \\
\hline Eosinophilic granuloma & $1(14.3 \%)$ & $1(14.3 \%)$ & $1(14.3 \%)$ & $2(28.6 \%)$ & $0(0)$ & $2(28.6 \%)$ & $0(0)$ & $0(0)$ & $0(0)$ & 7 \\
\hline Simple bone cyst & $0(0)$ & $0(0)$ & $1(20.0 \%)$ & $1(20.0 \%)$ & $1(20.0 \%)$ & $2(40.0 \%)$ & $0(0)$ & $0(0)$ & $0(0)$ & 5 \\
\hline Spinal meningioma & $0(0)$ & $0(0)$ & $1(20.0 \%)$ & $2(40.0 \%)$ & $2(40.0 \%)$ & $0(0)$ & $0(0)$ & $0(0)$ & $0(0)$ & 5 \\
\hline Gut-tail cyst & $0(0)$ & $0(0)$ & $3(75.0 \%)$ & $0(0)$ & $1(25.0 \%)$ & $0(0)$ & $0(0)$ & $0(0)$ & $0(0)$ & 4 \\
\hline Benign fibrous histiocytoma & $0(0)$ & $0(0)$ & $1(25.0 \%)$ & $1(25.0 \%)$ & $1(25.0 \%)$ & $0(0)$ & $1(25.0 \%)$ & $0(0)$ & $0(0)$ & 4 \\
\hline Fibromatosis & $0(0)$ & $0(0)$ & $0(0)$ & $0(0)$ & $2(66.7 \%)$ & $1(33.3 \%)$ & $0(0)$ & $0(0)$ & $0(0)$ & 3 \\
\hline $\begin{array}{l}\text { Diffuse giant cell tumor } \\
\text { of tendon sheath }\end{array}$ & $0(0)$ & $1(33.3 \%)$ & $1(33.3 \%)$ & $1(33.3 \%)$ & $0(0)$ & $0(0)$ & $0(0)$ & $0(0)$ & $0(0)$ & 3 \\
\hline Chondroblastoma & $1(33.3 \%)$ & $0(0)$ & $2(66.7 \%)$ & $0(0)$ & $0(0)$ & $0(0)$ & $0(0)$ & $0(0)$ & $0(0)$ & 3 \\
\hline Lipoma & $0(0)$ & $0(0)$ & $0(0)$ & $0(0)$ & $0(0)$ & $1(50.0 \%)$ & $1(50.0 \%)$ & $0(0)$ & $0(0)$ & 2 \\
\hline Phosphouria stromal tumor & $0(0)$ & $0(0)$ & $1(50.0 \%)$ & $0(0)$ & $0(0)$ & $0(0)$ & $1(50.0 \%)$ & $0(0)$ & $0(0)$ & 2 \\
\hline Osteoidosteoma & $0(0)$ & $1(50.0 \%)$ & $1(50.0 \%)$ & $0(0)$ & $0(0)$ & $0(0)$ & $0(0)$ & $0(0)$ & $0(0)$ & 2 \\
\hline Leiomyoma & $0(0)$ & $0(0)$ & $0(0)$ & $0(0)$ & $1(100.0 \%)$ & $0(0)$ & $0(0)$ & $0(0)$ & $0(0)$ & 1 \\
\hline Paget disease & $0(0)$ & $0(0)$ & $0(0)$ & $0(0)$ & $0(0)$ & $0(0)$ & $1(100.0 \%)$ & $0(0)$ & $0(0)$ & 1 \\
\hline Osteochondroma & $0(0)$ & $0(0)$ & $0(0)$ & $1(100.0 \%)$ & $0(0)$ & $0(0)$ & $0(0)$ & $0(0)$ & $0(0)$ & 1 \\
\hline
\end{tabular}

Chordoma is a relatively rare neoplasm and accounts for $1-4 \%$ of all primary malignant bone tumors which arise from embryonic remnants of notochord [6]. It has been reported that chordomas occur most commonly within the sacrum $(50-60 \%)$, followed by the spheno-occipital vertebrae (25-30\%), cervical region (10\%), and thoracolumbar vertebrae $(5 \%)$ and chordoma affects males more commonly than female [7]. Our results also showed the male predominance was most pronounced among 306 chordomas, accounting for $68.6 \%$ and the age of 51-70 yrs was the most common of age interval, which was concordant with the previous studies. The peak age in our cohort was the range of 51 to 60 and it was distinctly uncommon in patients younger than 30 years, only accounting for $5.9 \%(18 / 306)$. Furthermore, the peak age of chordoma was higher than that of chondrosarcomas, MPNST, and lymphoma.
Chondrosarcomas (CS) rank the second in the incidence of all primary malignant bone tumors, with reporting about 25\% incidence and following after osteosarcoma. Regarding age, it is more common in adults between 40 and 80 years old and is slightly more common in men [8]. CS constituted over 20.4\% of the malignant tumors in Mayo Clinic series and more than two-thirds of chondrosarcomas were in the trunk and the upper ends of the femur and humerus. CS was relatively rare and the incidence at the sacrum was $1.9 \%(24 / 1293)$ among all chondrosarcomas in the Mayo Clinic series [9]. However, in our cohort, the analysis of the clinical feature of CS showed an obvious predilection of male $(\mathrm{M}: \mathrm{F}=1.24$ : 1 ) and the peak age ranged from 41 to 50 years. Moreover, chondrosarcoma was the second common histological type at the region of the sacrum for the 


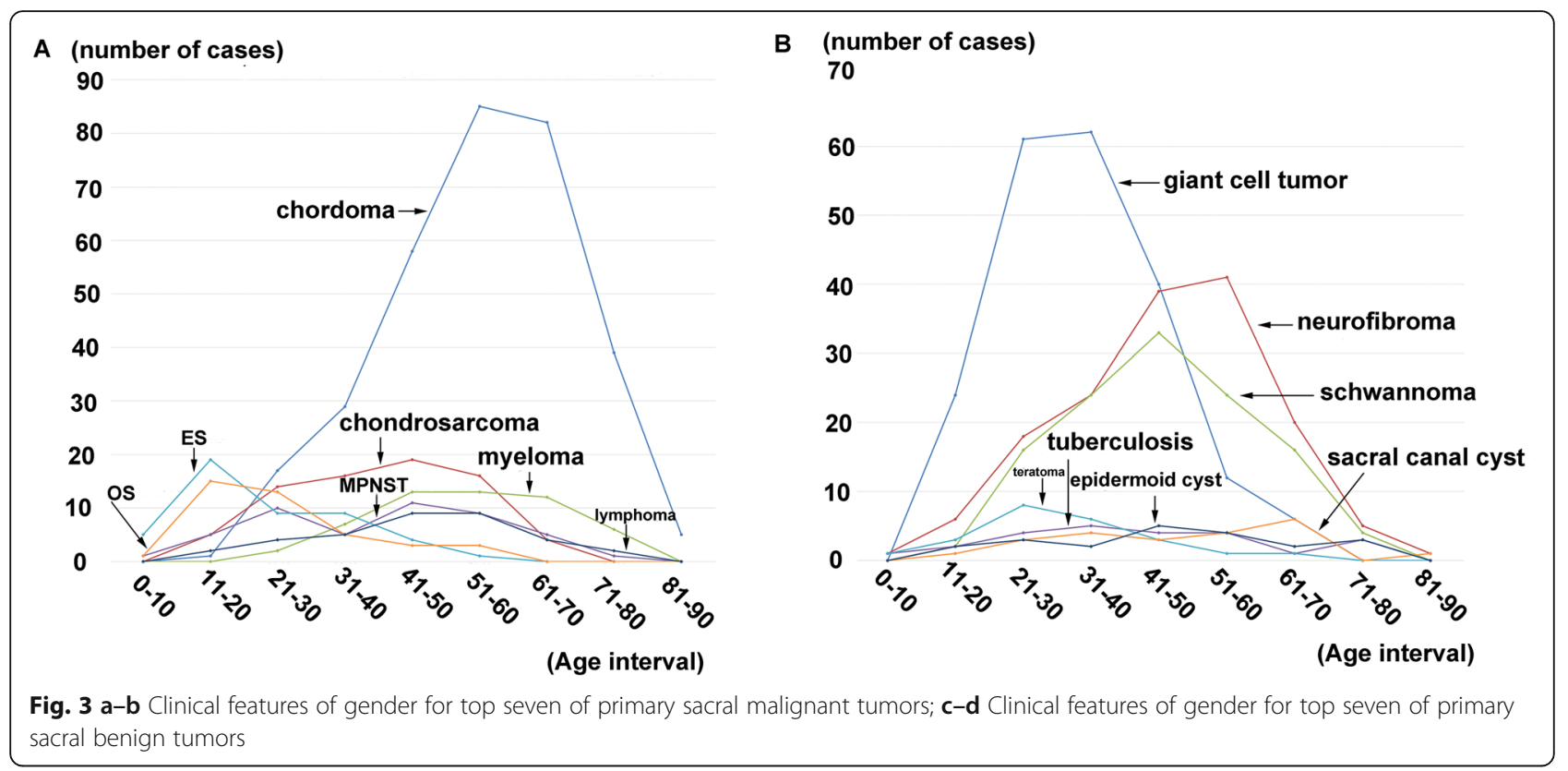

primary sacral malignant tumors and the incidence of CS among the malignant tumors was $10.3 \%$ (74/716).

Although myeloma and lymphoma are not the primary sacral tumors, they are more common lesions at the sacrum in the clinical practice. It is necessary to analyze their clinical features to distinguish them from primary malignant sacral tumors. Myeloma, a tumor of hematopoietic derivation, is the most common primary neoplasm of the bone. There were more than 5000 patients with myeloma documented in the Mayo Clinic files. They reported $67.7 \%$ were males and the largest concentration of age was in the sixth and seventh decades of life. The well-known rarity of myeloma in patients who were younger than 40 years was shown in the Mayo Clinic series [9]. Likewise, myeloma at the sacrum had the gender predilection (M: $\mathrm{F}=2.12: 1)$ and $67.9 \%$ of all myelomas were males in our series. The median age of myeloma was $54.1 \pm 13.2 \mathrm{yrs}$ and the peak age ranged from 41 to 50 years. Only two patients in our cohort were younger than 30 years and no patient was in the first and second decades of life. Generally, the clinical characteristics of sacral myeloma were similar to other bony myeloma. Bone lymphoma is a rare disease. It is estimated that bone lymphoma is accounting for about $5 \%$ of extranodal lymphomas and $3-7 \%$ of all malignant bone tumors [10]. Parker et al. first described the malignant lymphoma of bone and separated it from Ewing sarcoma [11]. The Mayo Clinic database showed the 905 cases of malignant lymphoma comprised of $12.7 \%$ of the malignant bone tumors in their series and males

Table 5 Gender distribution of sacral malignant tumors

\begin{tabular}{|c|c|c|c|c|c|c|c|c|c|c|}
\hline \multirow[t]{2}{*}{ Histology } & \multirow{2}{*}{$\begin{array}{l}\text { No. } \\
\text { No. }\end{array}$} & \multicolumn{2}{|c|}{ Male } & \multicolumn{2}{|c|}{ Female } & \multirow[t]{2}{*}{$\mathrm{M}: \mathrm{F}$} & \multirow{2}{*}{$\begin{array}{l}\text { Age } \\
\text { range } \\
\text { (years) }\end{array}$} & \multicolumn{3}{|c|}{ Mean \pm SD (age) } \\
\hline & & No. & $\%$ & No. & $\%$ & & & Male & Female & Total $P$ value \\
\hline Chordoma & 316 & 210 & $66.5 \%$ & 106 & $33.5 \%$ & $1.98: 1$ & $18-86$ & $56.1 \pm 13.3$ & $54.1 \pm 14.4$ & $\begin{array}{l}55.4 \pm 13.7 \\
P=0.236\end{array}$ \\
\hline Chondrosarcoma & 74 & 41 & $55.4 \%$ & 33 & $44.6 \%$ & $1.24: 1$ & $17-69$ & $37.7 \pm 14.8$ & $44.9 \pm 10.0$ & $\begin{array}{l}40.9 \pm 13.3 \\
P=0.015\end{array}$ \\
\hline Myeloma & 53 & 36 & $67.9 \%$ & 17 & $32.1 \%$ & $2.12: 1$ & $22-78$ & $53.4 \pm 14.4$ & $55.6 \pm 10.6$ & $\begin{array}{l}54.1 \pm 13.2 \\
P=0.567\end{array}$ \\
\hline $\begin{array}{l}\text { Malignant peripheral } \\
\text { nerve sheath tumor }\end{array}$ & 47 & 19 & $40.4 \%$ & 28 & $59.6 \%$ & $0.68: 1$ & $8-75$ & $40.4 \pm 18.3$ & $41.0 \pm 15.8$ & $\begin{array}{l}40.8 \pm 16.7 \\
P=0.903\end{array}$ \\
\hline Ewing sarcoma & 47 & 24 & $51.1 \%$ & 23 & $48.9 \%$ & $1.04: 1$ & $2-56$ & $23.8 \pm 13.1$ & $22.7 \pm 12.8$ & $\begin{array}{l}23.3 \pm 12.8 \\
P=0.791\end{array}$ \\
\hline Osteosarcoma & 40 & 23 & $57.5 \%$ & 17 & $42.5 \%$ & $1.35: 1$ & $10-58$ & $29.0 \pm 13.6$ & $22.0 \pm 10.3$ & $\begin{array}{l}26.0 \pm 12.7 \\
P=0.085\end{array}$ \\
\hline Lymphoma & 35 & 15 & $42.9 \%$ & 20 & $57.1 \%$ & $0.75: 1$ & $20-78$ & $46.2 \pm 16.4$ & $49.2 \pm 14.3$ & $\begin{array}{l}47.9 \pm 15.0 \\
P=0.574\end{array}$ \\
\hline
\end{tabular}


Table 6 Gender distribution of sacral benign tumors and tumor-like lesions

\begin{tabular}{|c|c|c|c|c|c|c|c|c|c|c|}
\hline \multirow[t]{2}{*}{ Histology } & \multirow{2}{*}{$\begin{array}{l}\text { No. } \\
\text { No. }\end{array}$} & \multicolumn{2}{|c|}{ Male } & \multicolumn{2}{|c|}{ Female } & \multirow[t]{2}{*}{$\mathrm{M}: \mathrm{F}$} & \multirow{2}{*}{$\begin{array}{l}\text { Age } \\
\text { range } \\
\text { (years) }\end{array}$} & \multicolumn{3}{|c|}{ Mean \pm SD (age) } \\
\hline & & No. & $\%$ & No. & $\%$ & & & Male & Female & Total $P$ value \\
\hline Giant cell tumor & 205 & 95 & $46.3 \%$ & 110 & $53.7 \%$ & $0.86: 1$ & $11-67$ & $32.7 \pm 10.3$ & $35.8 \pm 12.5$ & $\begin{array}{l}34.4 \pm 11.6 \\
P=0.057\end{array}$ \\
\hline Neurofibroma & 155 & 69 & $44.5 \%$ & 86 & $55.5 \%$ & $0.80: 1$ & $9-83$ & $44.6 \pm 13.8$ & $48.4 \pm 14.9$ & $\begin{array}{l}46.7 \pm 14.5 \\
P=0.108\end{array}$ \\
\hline Schwannoma & 119 & 60 & $50.4 \%$ & 59 & $49.6 \%$ & $1.02: 1$ & $13-79$ & $44.6 \pm 13.1$ & $47.7 \pm 13.9$ & $\begin{array}{l}46.1 \pm 13.5 \\
P=0.212\end{array}$ \\
\hline Tuberculosis & 24 & 8 & $33.3 \%$ & 16 & $66.7 \%$ & $0.50: 1$ & $8-76$ & $46.9 \pm 21.6$ & $39.5 \pm 17.7$ & $\begin{array}{l}42.0 \pm 18.9 \\
P=0.380\end{array}$ \\
\hline Teratoma & 23 & 4 & $17.4 \%$ & 19 & $82.6 \%$ & $0.21: 1$ & $5-62$ & $33.8 \pm 17.3$ & $31.3 \pm 12.4$ & $\begin{array}{l}31.7 \pm 12.9 \\
P=0.741\end{array}$ \\
\hline Sacral canal cysts & 22 & 11 & $50.0 \%$ & 11 & $50.0 \%$ & $1.00: 1$ & $19-81$ & $46.0 \pm 21.2$ & $51.5 \pm 12.3$ & $\begin{array}{l}48.8 \pm 17.1 \\
P=0.461\end{array}$ \\
\hline Epidermoid cyst & 21 & 4 & $19.0 \%$ & 17 & $81.0 \%$ & $0.24: 1$ & 19-78 & $32.8 \pm 23.0$ & $50.3 \pm 16.4$ & $\begin{array}{l}47.0 \pm 18.6 \\
P=0.089\end{array}$ \\
\hline
\end{tabular}

predominated at a ratio of 4 to 3 in their cohort. In our cohort, approximately $51.4 \%$ of lymphoma occurred in patients between 41 and 60 years, with a peak incidence in the fifth and sixth decade of life. Only $5.7 \%$ of the patients with lymphoma were younger than 20 years and no one was younger than 10 years old. However, our series revealed lymphoma at the sacrum had the female predilection (M: $\mathrm{F}=0.75: 1)$, which was not concordant with the Mayo Clinic experience.

Malignant peripheral nerve sheath tumors (MPNS $\mathrm{T}$ ) include malignant schwannoma (malignant peripheral schwannoma) and neurofibrosarcoma. MPNS
$T$ represents a relatively common subtype of soft tissue sarcoma and is particularly likely to occur in individuals with type 1 neurofibromatosis (NF1) [1215]. A SEER database analysis showed 64 MPNST in the spinal location. Their mean age at diagnosis was 50.9 years with more patients in the higher age group and $56 \%$ of patients were male. However, it had no description of the incidence at the sacrum [16]. In our cohort, the analysis of the clinical feature of MPNST showed an obvious predilection of female ( $\mathrm{M}: \mathrm{F}=0.68: 1)$ and the peak age ranged from 41 to 50 years. Our result showed the clinical

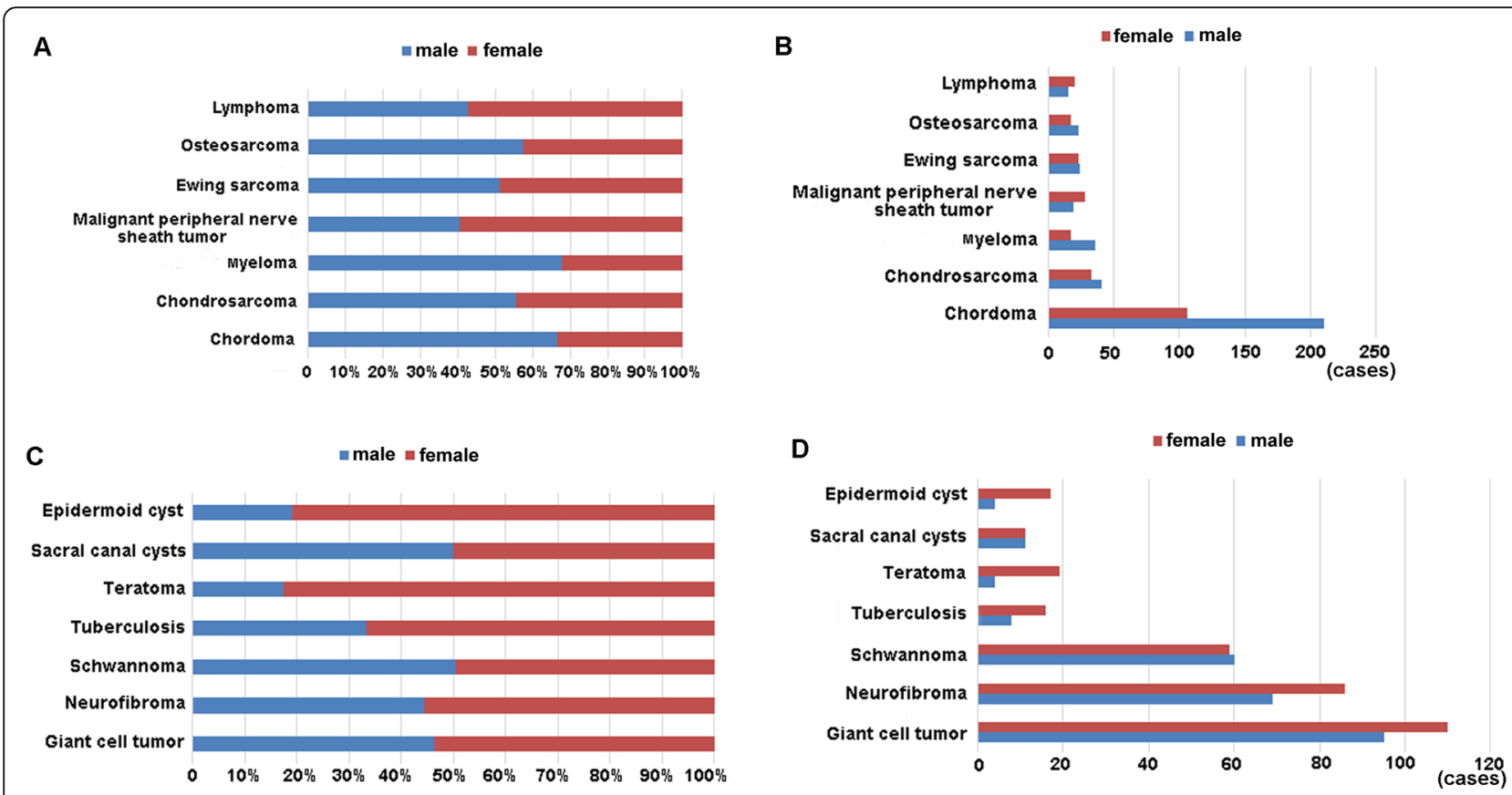

Fig. 4 a Age distribution for top seven of primary sacral malignant tumors. $N$ = numbers of patients; $\mathbf{b}$ Age distribution for top seven of primary sacral benign tumors. $N$ = numbers of patients 
Table 7 Comparision of location distribution of top two histologic types

\begin{tabular}{llll}
\hline Location & Chordoma $(\boldsymbol{n}=\mathbf{3 1 6})$ & Giant cell tumor $(\boldsymbol{n}=\mathbf{2 0 5})$ & $\boldsymbol{P}$ value \\
\hline Region $\mathrm{S}_{1}$ or $\mathrm{S}_{2}$ or $\mathrm{S}_{1-2}$ & $5(1.6 \%)$ & $80(39.0 \%)$ & $11(5.4 \%)$ \\
Region $\mathrm{S}_{3}$ and below $\mathrm{S}_{3}$ & $145(45.9 \%)$ & $114(55.6 \%)$ \\
Associated with both two regions & $166(52.5 \%)$ & \\
\hline
\end{tabular}

characteristic of age predilection was in concordance with the previous study in the SEER database, but gender predilection of MPNST at the sacrum was not similar to the result of the SEER database [16].

Ewing sarcoma (ES) and osteosarcoma (OS) are more frequent for young patients. The incidence of ES is a little higher than that of OS at the sacrum in the present study. ES is a distinctive, small, round cell sarcoma that is considered one of the most lethal of all bone tumors. In the Mayo Clinic database, ES comprised $8.6 \%$ of the total malignant tumors and had a distinct predilection for males (62\%). Furthermore, approximately $75 \%$ were in the first two decades of life and the incidence of ES at the sacrum accounted for 5.9\% (36/611) of all patients with ES [9]. The sacrum is not the frequent site for Ewing sarcoma. In our PKUPH database, Ewing sarcoma is located at the sixth top of all sacral malignant tumors. The peak incidence was in the second decade $(40.4 \%$ of all 47 Ewing sarcomas), followed by the third and fourth decades $(38.2 \%)$ and it had no predilection of gender, which was not concordant with the Mayo Clinic experience. Osteosarcoma is the most common malignant

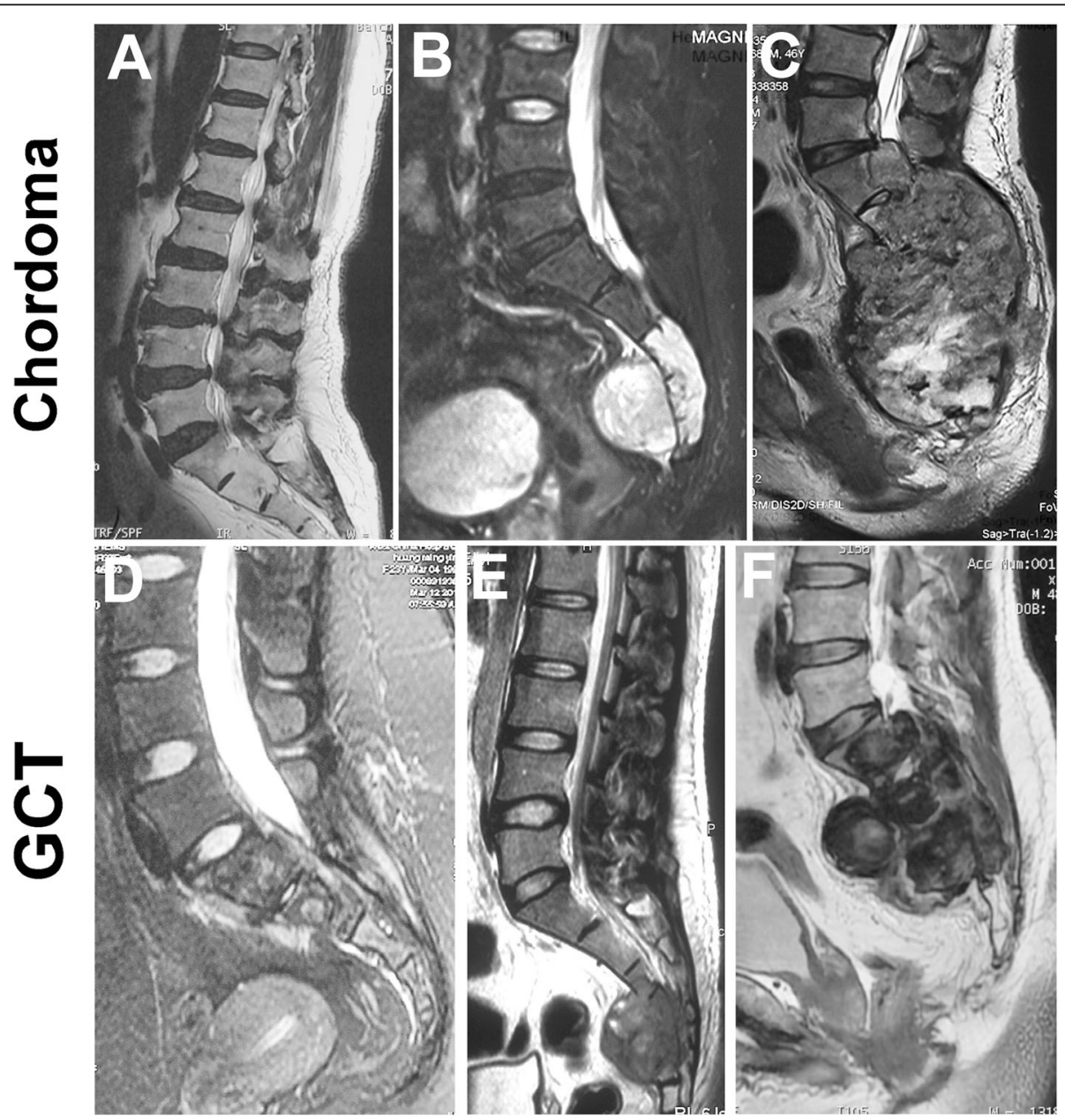

Fig. 5 Location distribution of chordoma and giant cell tumor. a Chordomas at the Region $S_{1}$ or $S_{2}$ or $S_{1-2}$ accounting for 1.6\% (5/316); $\mathbf{b}$ Chordomas at the Region $\mathrm{S}_{3}$ or below $\mathrm{S}_{3}$ accounting for $45.9 \%$ (145/316); c Chordomas associated with both high and low levels accounting for $52.5 \%$ (166/316); d GCT at the Region $S_{1}$ or $S_{2}$ or $S_{1-2}$ accounting for $39.0 \%$ (80/205); e GCT at the Region $S_{3}$ or below $S_{3}$ accounting for $5.4 \%$ (11/ 205); $\mathbf{f}$ GCT associated with both high and low levels accounting for $55.6 \%(114 / 205)$ 
bone tumor. Mayo Clinic series files recorded 1952 osteosarcomas, accounting for $27.5 \%$ of all malignant tumors and $19.2 \%$ of all bone tumors and approximately $58 \%$ of patients with OS were male. In their database, the incidence of OS at the sacrum accounted for $2.0 \%$ of all patients with OS and the anatomic site around the knee was the most common site. The second decade was the most common age distribution and among 1952 osteosarcomas, 192 patients were older than 60 years who had pre-existing condition such as Paget disease, previous radiation, infarct, chronic osteomyelitis, and cyst of degenerative joint disease as the second peak [9]. According to our results, osteosarcoma at the sacrum was not frequent as the site around the knee and placed as the sixth top of all primary sacral malignant tumors. Although only one patient with the sacral OS was in the first decade of life, the peak incidence was in the second decade (37.5\% of all 40 osteosarcomas), followed by the third decade $(32.5 \%)$. We noticed no one patient aged more than 60 years. This result demonstrated that the age distribution of sacral osteosarcoma had the peak age of 11-20 and did not show another age peak of more than 60 years. Moreover, osteosarcoma was not common in the region of the sacrum. Thus, when an adolescent patient presents with a malignant tumor, we should take these two histologic types into consideration.

Our PKUPH database showed that giant cell tumor $(30.6 \%, 205 / 669)$ was the most frequent in the cohort of benign tumors and tumor-like lesions, followed by neurofibroma $(23.2 \%, 155 / 669)$ and schwannoma $(17.8 \%$, 119/669). The clinical characteristics of primary sacral benign tumors were distinct from the one of spinal benign tumors. Some rare histologic types should be considered when the differential diagnosis [17-23]. It has been reported that hemangioma was the most frequent benign primary spine tumor in one hospital of China, which was different from the region of the sacrum and our database showed giant cell tumor was the most common histological type at the sacrum [1]. Hemangioma at the sacrum accounted for $2.1 \%(14 / 669)$ in the cohort of benign tumor and tumor-like lesions. It illustrated that hemangioma was not a frequent tumor at the sacrum, which was different from the characteristics of the mobile spine. It is more important to distinguish some benign histologic types such as giant cell tumor, hemangioma, and aneurysmal bone cyst, due to their higher vascularity and intraoperative hemorrhage. Thus, although these lesions are benign, more attention should be paid to the problem of intraoperative blood loss.

Giant cell tumor (GCT) is an invasive benign bone tumor consisting of proliferative mononuclear cells and osteoclast-like multinucleated giant cells. In the present study, GCT was the most common benign tumor at the sacrum. This result was concordant with the study of
Zhou et al. about the epidemiological feature of all spinal tumors [1]. The Mayo Clinic series showed the female predominated in bone GCT, with 376 females and 295 males [9]. However, Niu et al. reported 621 patients with GCT in the extremity and male predominance (1.4:1) was observed in their series [24]. Their epidemiological feature of extremities was different from the characteristics of our sacral GCT and this illustrated that predominate gender may depend on the anatomical site. Our cohort also had 110 cases of females, accounting for $53.7 \%$ of all GCTs in our series. Approximately $79.5 \%$ of GCT occurred in patients between 21 and 50 years, with a peak incidence in the third and fourth decade of life. Only $8.8 \%$ of the patients with GCT were older than 50 years and only $11.7 \%$ of GCT occurred in patients before 20 years old. Furthermore, no one was younger than 10 years old. Thus, it illustrated that giant cell tumors are not common in the adolescent population.

Benign peripheral neurogenic tumors include neurofibroma and peripheral schwannoma. Neurogenic tumors arising from the sacrum are rare, with only about $7 \%$ of intraspinal neurogenic tumors involving the sacrum. Neurofibromas can occur in any site, both deep soft tissue and superficial cutaneous lesions. They are usually painless and they are often excised for cosmetic purposes. Individuals with NF1 may have multiple neurofibromas that need excision for functional purpose as well as to exclude the possibility of malignant transformation. The analysis of the clinical feature of neurofibroma in our series showed a little predilection of females $(M: F=0.80: 1)$ and the peak age ranged from 41 to 60 years. Meanwhile, schwannomas are relatively common benign lesions of the peripheral nerves, which are thought to derive from Schwann cell. They affect all age groups and are usually solitary sporadic tumors. Schwannomas can also develop along the spine adjacent to the neural foramina and frequently show a "target sign" on imaging that can be very suggestive of this specific diagnosis. They are usually slow-growing and often discovered incidentally. It has been reported that sacral schwannomas typically occur in middle-aged patients without any predilection for gender. Pennington et al. performed a systematic review and reported that presacral schwannoma can reasonably be treated with either en bloc or piecemeal excision and recurrence was infrequent. In their review, the patients showed no gender predilection [25]. Our database analysis revealed the clinical feature of schwannoma also had no gender predilection and the peak age ranged from 31 to 60 years. This result was concordant with the result of the previous study in the literature. Neurofibroma and schwannoma are always located at a higher level of the sacrum, which is distinct from the teratoma and we can consider this feature when the differential diagnosis is performed. 
There were several limitations to the present study. Firstly, although the present cohort in our tumor center is large, the data drawn from the present analysis may not necessarily reflect the epidemiologic characteristics of the whole nation. Secondly, the present data lacked the information on the prognosis for all patients. Thus, in the next step, we will collect more information about the oncological prognosis of all patients.

In conclusion, the large cohort of sacral tumors and tumor-like lesions in our database may reveal their clinical characteristics in China and clinical feature of age, gender, histologic type, and anatomic site for sacral tumors and tumor-like lesions is fairly distinct from the mobile spine and extremities.

\section{Acknowledgements}

Not applicable.

\section{Conflict of interest statement and ethical approval}

The authors declare that they have no conflict of interest. This article does not contain any studies with human participants or animals performed by any of the authors and informed consent was obtained from all individual participants included in the study.

\section{Authors' contributions}

WJ carried out the data analysis and drafted the manuscript. LDS collected data and performed the statistical analysis YRL, TXD, and YTQ participated in its design. GW designed the study and reviewed the article. All authors have been actively involved in the drafting and critical revision of the manuscript, and each provided final approval of the version to be published.

\section{Funding}

This work was supported by the Natural Science Foundation of China (NO: 81702657).

\section{Availability of data and materials}

All data generated or analyzed during this study was included in this published article.

\section{Ethics approval and consent to participate}

This study was approved by the Institutional Review Board/Ethics Committee of the authors' institution and the study was performed according to the Helsinki Declaration guidelines. Informed consent was obtained from the patients prior to enrolling in the study.

\section{Consent for publication}

We obtained consent for publication from the patients.

\section{Competing interests}

The authors declare that they have no competing interests.

Received: 11 May 2020 Accepted: 5 October 2020

Published online: 12 November 2020

\section{References}

1. Zhou Z, Wang X, Wu Z, Huang W, Xiao J. Epidemiological characteristics of primary spinal osseous tumors in Eastern China. World J Surg Oncol. 2017; 15:73.

2. Junior RC, Pereira MG, Garcia PB, Santos PA, Cavalcanti Ados S, Meohas W. Epidemiological study on giant cell tumor recurrence at the Brazilian National Institute of Traumatology and Orthopedics. Rev Bras Ortop. 2016; 51:459-65.

3. Puri A, Agarwal MG, Shah M, Srinivas CH, Shukla PJ, Shrikhande SV, Jambhekar NA. Decision making in primary sacral tumors. Spine J. 2009;9: 396-403.
4. Chi JH, Bydon A, Hsieh P, Witham T, Wolinsky JP, Gokaslan ZL. Epidemiology and demographics for primary vertebral tumors. Neurosurg Clin N Am. 2008;19:1-4.

5. Boriani S, Biagini R, De lure F, Andreoli I, Campanacci L, De Fiore M, Zanoni A. Primary bone tumors of the spine: a survey of the evaluation and treatment at the Istituto Ortopedico Rizzoli. Orthopedics. 1995;18:993-1000.

6. McMaster ML, Goldstein AM, Bromley C, Ishibe N, Parry DM. Chordoma: incidence and survival patterns in the United States, 1973-1995. Cancer Causes Control. 2001;12:1-11.

7. van Wulfften Palthe ODR, Tromp I, Ferreira A, Fiore A, Bramer JAM, van Dijk NC, DeLaney TF, Schwab JH, Hornicek FJ. Sacral chordoma: a clinical review of 101 cases with 30-year experience in a single institution. Spine J. 2019;19: 869-79.

8. DelaGarza-Montano P, Estrada-Villasenor E, Dominguez Rubio R, MartinezLopez V, Avila-Luna A, Alfaro-Rodriguez A, Garciadiego-Cazares D, Carlos A, Hernandez-Perez AD, Bandala C. Epidemiological aspects of osteosarcoma, giant cell tumor and chondrosarcoma musculoskeletal tumors-experience of the National Rehabilitation Institute, Mexico City. Asian Pac J Cancer Prev. 2015;16:6451-5.

9. Unni KK, Inwards CY: Dablin's Bone Tumors(Sixth Edition)..

10. Wang Y, Li J, Wei R, Liu C, Nataraj A, Yan J. Prognostic Factors Associated With Bone Lymphoma Primarily Presenting in the Spine. Spine (Phila Pa 1976). 2019;44:185-94.

11. Parker F, Jackson H. Primary reticulum cell sarcoma of bone. Surg Gynecol Obstet. 1939;68:45-53.

12. Dodd LG, Bui MM: Atlas of soft tissue and bone pathology.

13. Wang T, Yin H, Han S, Yang X, Wang J, Huang Q, Yan W, Zhou W, Xiao J. Malignant peripheral nerve sheath tumor (MPNST) in the spine: a retrospective analysis of clinical and molecular prognostic factors. J NeuroOncol. 2015;122:349-55.

14. Zhu B, Liu X, Liu Z, Yang S, Liao Hl, Jiang L, Wei F. Malignant peripheral nerve sheath tumours of the spine: clinical manifestations, classification, treatment, and prognostic factors. Eur Spine J. 2012;21:897-904.

15. Lang $N$, Liu XG, Yuan HS. Malignant peripheral nerve sheath tumor in spine: imaging manifestations. Clin Imaging. 2012;36:209-15.

16. Stadler JA 3rd, Qadri U, Tang JA, Scheer JK, Melkonian SC, Smith ZA, Lam SK. Malignant peripheral nerve sheath tumors of the spine: a SEER database analysis. J Clin Neurosci. 2014;21:1106-11.

17. Fumino S, Tajiri T, Usui N, Tamura M, Sago H, Ono S, Nosaka S, Yoneda A, Souzaki R, Higashi M, et al. Japanese clinical practice guidelines for sacrococcygeal teratoma, 2017. Pediatr Int. 2019;61:672-8.

18. Zhelnin KE, Gebhard GM, Mirsky DM, Oliver SC, Lovell MA, Galambos C, Crombleholme TM, McCourt EA. Pediatric intraocular immature teratoma associated with sacrococcygeal teratoma. Pediatr Dev Pathol. 2017;20:240-4.

19. Simpson PJ, Wise KB, Merchea A, Cheville JC, Moir C, Larson DW, Dozois EJ. Surgical outcomes in adults with benign and malignant sacrococcygeal teratoma: a single-institution experience of 26 cases. Dis Colon Rectum. 2014;57:851-7.

20. Beechar VB, Zinn PO, Heck KA, Fuller GN, Han I, Patel AJ, Ropper AE. Spinal epidermoid tumors: case report and review of the literature. Neurospine. 2018;15:117-22.

21. Maeda T, Mishima K, Imanishi J, Shirahata M, Suzuki T, Adachi Jl, Sasaki A, Nishikawa R. An epidermoid cyst of the thoracic spine in an elderly patient. World Neurosurg. 2019;127:113-6.

22. Lin YP, Li YJ, Chen BL, Guo YH. Lumbar laminotomy and replantation for the treatment of adult spinal epidermoid cyst: A case report. Medicine (Baltimore). 2018;97:e9334.

23. Cincu R, Lázaro JF, Liesa JL, Callizo JR. Dorsal intramedullary spinal epidermoid cysts: Report of two cases and review of literature. Indian J Orthop. 2007:41:395-7.

24. Niu X, Zhang Q, Hao L, Ding Y, Li Y, Xu H, Liu W. Giant cell tumor of the extremity: retrospective analysis of 621 Chinese patients from one institution. J Bone Joint Surg Am. 2012;94:461-7.

25. Pennington Z, Westbroek EM, Ahmed AK, Cottrill E, Lubelski D, Goodwin ML, Sciubba DM. Surgical management of giant presacral schwannoma: systematic review of published cases and meta-analysis. J Neurosurg Spine. 2019.

\section{Publisher's Note}

Springer Nature remains neutral with regard to jurisdictional claims in published maps and institutional affiliations. 